\title{
COLOUR DOPPLER STUDY OF FOETOMATERNAL CIRCULATION IN PIH, OLIGOHYDRAMNIOS AND ITS PERINATAL OUTCOME
}

\author{
Bhavana $S^{1}$, Sowmya $S^{2}$
}

1 Junior Consultant, Department of Obstetrics and Gynaecology, Motherhood Hospital, Bangalore, Karnataka, India. ${ }_{2}^{2}$ Assistant Professor, Department of Obstetrics and Gynaecology, Basaveshwara Medical College, Chitradurga, Karnataka, India.

\begin{abstract}
BACKGROUND

Hypertensive disorders of pregnancy are one of the most common complications that affect the mother. It is one of the leading causes of maternal and foetal morbidity and mortality. Oligohydramnios is defined by Phelan ${ }^{1}$ as AFI $<5 \mathrm{~cm}^{\mathrm{but}} \mathrm{Jeng}{ }^{2}$ et al proposed a cut off of $8 \mathrm{cms}$ demonstrating increased incidence of meconium staining, caesarean delivery for foetal distress. Abnormal foetal heart rate pattern and Apgar score of 7/less at one minute when AFI was $<8$. The aim of the study is to evaluate and study the foetomaternal circulation using colour Doppler in hypertensive disorders of pregnancy and oligohydramnios in third trimester so that we may predict various complications that may arise and to follow the foetal outcome.
\end{abstract}

\section{MATERIALS AND METHODS}

This observational study has been carried out in the department of Obstetrics and Gynaecology, Sri Adichunchanagiri Institute of Medical Sciences, B. G. Nagara, in pregnant women attending OPD/admitted and satisfying the inclusion (PIH and oligohydramnios in third trimester) and exclusion criteria, during the period November 2012 to October 2014. Doppler study was conducted in all these high-risk cases.

\section{RESULTS}

Out of 100 high risk cases, 56\% had hypertension, $24 \%$ had Oligohydramnios and 20\% had both hypertension and Oligohydramnios. Majority of the patients (48\%) were in the mean age group of 21-25 years. In uterine artery Doppler study, abnormal RI $>0.6$ was present in $11 \%$, PI $>1.1$ in $25 \%$ and S/D ratio $>2.6$ in $24 \%$. 39\% showed persistence of notching in uterine artery. Umbilical artery Doppler revealed, abnormal RI $>0.6$ in 58\%, PI $>1$ in 39\% and abnormal S/D ratio $>3$ in 29\%. Majority were term at the time of termination. $58 \%$ of neonates had a mean birth weight of $<2.5 \mathrm{~kg}$. Meconium staining was present in $40 \%$ of babies and low APGAR $<7$ at 1 min and 5 mins in 19\%. NICU admission was needed for 38\% of babies. 12\% perinatal mortality was observed.

\section{CONCLUSION}

Present study conducted in high risk pregnancies with Doppler parameters, revealed those with abnormal Doppler study had an adverse outcome. Hence, Doppler study has got a better prediction of adverse perinatal outcome and thus provide the obstetrician adequate time during which early intervention can be made, to improve foetal outcome.

\section{KEY WORDS}

Hypertension, Oligohydramnios, Doppler Study, Perinatal Mortality.

HOW TO CITE THIS ARTICLE: Bhavana S, Sowmya S. Colour Doppler study of foetomaternal circulation in PIH, oligohydramnios and its perinatal outcome. J. Evolution Med. Dent. Sci. 2018;7(47):5134-5138, DOI: 10.14260/jemds/2018/1139

\section{BACKGROUND}

Hypertensive disorders of pregnancy are one of the most common complications that effects the mother. Preeclampsia is a pregnancy-specific syndrome characterized by reduced organ perfusion secondary to vasospasm and endothelial pathophysiology. The reported incidence of preeclampsia is $6-10 \%, 3,4,5$ This condition is the leading cause of maternal mortality and is responsible for considerable perinatal morbidity and mortality.

Abnormal placentation is one of the initial event. It causes inadequate trophoblastic invasion of the maternal spiral

'Financial or Other Competing Interest': None.

Submission 13-07-2018, Peer Review 10-08-2018,

Acceptance 16-08-2018, Published 19-11-2018.

Corresponding Author:

Dr. Sowmya $S$,

Suneetha Nursing Home,

Near Air Station, C. K. Pura Extension,

Chitradurga-577501, Karnataka, India.

E-mail: sowmyas.1512@gmail.com

DOI: $10.14260 /$ jemds $/ 2018 / 1139$

(c) $(7)$ arterioles and raises the vascular resistance resulting in decreased utero-placental perfusion. As a result of impaired uteroplacental blood flow, manifestations of preeclampsia may be seen in the fetoplacental unit like intrauterine growth restriction (IUGR), oligohydramnios, placental abruption and non-reassuring foetal status (NST).

Antepartum foetal surveillance is based on the idea that identification and timed delivery of the hypoxic foetus can prevent intrauterine foetal death and decrease the risk of long term adverse effects. The traditional methods of foetal surveillance like NST, foetal heart monitoring, foetal BPP are no more ideal tests because of their inability to detect early stages of foetal distress.

Doppler technique has been applied to investigate the foetal, fetoplacental, uteroplacental circulation, as it is a noninvasive technique and has a high diagnostic and prognostic evaluation. Doppler is considered to be the best tool in investigating and assessing accurate changes in foetomaternal circulation and to predict perinatal outcome so as to take decision for appropriate intervention. 
The availability of colour Doppler facility in Adichunchanagiri Institute of Medical Sciences, facilitated the study of role of colour Doppler evaluation of Foetomaternal circulation in hypertensive disorders of pregnancy and oligohydramnios.

\section{Aims and Objectives}

The aim of the study is to evaluate and study the foetomaternal circulation using colour Doppler in hypertensive disorders of pregnancy and oligohydramnios in third trimester so that we may predict various complications that may arise because of the above mentioned and to follow the foetal outcome.

\section{MATERIALS AND METHODS \\ Design}

The study was observational study.

\section{Study Period}

Two year.

\section{Sample Size}

Patients attending Sri Adichunchanagiri Institute of Medical Sciences with complains of PROM were examined and subjects fulfilling inclusion criteria were selected for the study. Study by convenient sample size technique since the duration of the study was 2 Year.

\section{Source of Data}

This observational study Conducted on 100 patients, was carried out in the department of Obstetrics and Gynaecology, out of 100 high risk cases, 56\% had hypertension, 24\% had Oligohydramnios and $20 \%$ had both hypertension and Oligohydramnios. The patients were included in the trial after due consideration of inclusion and exclusion criteria. Majority of the patients (48\%) were in the mean age group of 21-25 years, Sri Adichunchanagiri Institute of Medical Sciences, B. G. Nagara, in pregnant women attending OPD/admitted and satisfying the inclusion and exclusion criteria for 24 months. Study by convenient sampling technique since the duration of the study was 24 Months.

\section{Inclusion Criteria}

Colour Doppler Study in Pregnant Women with >28 Weeks of Gestation having-

a) Hypertensive disorders of pregnancy.

- Gestational Hypertension.

- Pre-Eclampsia.

- Eclampsia.

b) Oligohydramnios: $\mathrm{AFI}<8 \mathrm{~cm}$.

\section{Exclusion Criteria}

\section{Pregnant Women with-}

- Chronic Renal Diseases.

- Severe Malnutrition.

- Chronic Hypertension.

- Hypertension due to other causes like vascular, endocrinal, neurogenic.

- Symmetrical IUGR due to genetic causes and infection, chromosomal disorders occurring in $1^{\text {st }}$ trimester.

\section{Collection of Data}

The salient features of proforma included name, age, obstetrical history, history of present illness including headache, visual disturbance, epigastric pain, increased blood pressure on antenatal check-up, decreased foetal movements and past and personal history of pre-eclampsia, the findings of general physical examination (GPE) and systemic examination especially abdominal and vaginal examination. Patients were assessed on the basis of history, clinical examination, ultrasound and laboratory investigations.

\section{RESULTS}

\begin{tabular}{|c|c|c|}
\hline Age (Years) & No. of Cases & Percentage \\
\hline$<20$ & 19 & $19 \%$ \\
\hline $21-25$ & 48 & $48 \%$ \\
\hline $26-30$ & 28 & $28 \%$ \\
\hline $31-35$ & 6 & $6 \%$ \\
\hline $36-40$ & 0 & $0 \%$ \\
\hline Total & $\mathbf{1 0 0}$ & $\mathbf{1 0 0} \%$ \\
\hline \multicolumn{2}{|c|}{ Table 1. Age of Patients in Present Study } \\
\hline
\end{tabular}

In present study the age of patients was from 18 years to 35 years. Maximum no. of patients were in $21-25$ year age groups i.e. $48 \%$ and none in $36-40$ years age group.

\begin{tabular}{|c|c|c|}
\hline Age (Years) & No. of Cases & Percentage \\
\hline Hypertension & 56 & $56 \%$ \\
\hline Oligohydramnios & 24 & $24 \%$ \\
\hline HTN + Oligohydramnios & 20 & $20 \%$ \\
\hline
\end{tabular}

Table 2. Distribution of Cases according to Complications

\section{Distribution of Cases according to Complications}

Among 100 high risk cases, 56\% were complicated with hypertension, $24 \%$ had Oligohydramnios and $20 \%$ were complicated with both hypertension and Oligohydramnios

\begin{tabular}{|c|c|c|c|c|}
\hline \multirow{2}{*}{$\begin{array}{c}\text { Age } \\
\text { (Years) }\end{array}$} & \multicolumn{2}{|c|}{ HTN (76) } & \multicolumn{2}{c|}{ Oligohydramnios (24) } \\
\cline { 2 - 5 } & Number & Percentage & Number & Percentage \\
\hline$<20$ & 15 & 19.7 & 4 & 16.6 \\
\hline $21-25$ & 34 & 44.7 & 14 & 58.3 \\
\hline $26-30$ & 22 & 28.9 & 6 & 25 \\
\hline$>30$ & 5 & 6.5 & 0 & 0 \\
\hline
\end{tabular}

Table 3. Age Distribution according to High Risk Category

\section{Age Distribution according to High Risk Category}

Majority of the patients, in both hypertension group (44.7\%) and Oligohydramnios group (58.3\%) belonged to mean age group of 21-25 years.

\begin{tabular}{|c|c|c|}
\hline Class & No. of Cases & Percentage \\
\hline Upper & 20 & $20 \%$ \\
\hline Middle & 34 & $34 \%$ \\
\hline Lower & 46 & $46 \%$ \\
\hline Total & $\mathbf{1 0 0}$ & $\mathbf{1 0 0 \%}$ \\
\hline \multicolumn{2}{|c|}{ Table 4. Socioeconomic Status of the Patients } \\
\hline
\end{tabular}

Socioeconomic Status of the Patients

Patients were categorized based on their socioeconomic status into three division's viz. Upper middle and lower, according to Kuppuswamy Scale. 


\begin{tabular}{|c|c|c|}
\hline Parity & No. of Cases & Percentage \\
\hline Primi & 51 & $51 \%$ \\
\hline Multi & 49 & $49 \%$ \\
\hline Total & $\mathbf{1 0 0}$ & $\mathbf{1 0 0} \%$ \\
\hline \multicolumn{2}{|c|}{ Table 5. Parity of Patients } \\
\hline
\end{tabular}

\section{Parity of Patients}

Patients were recruited for the study irrespective of their parity, out of 100 patients $51 \%$ of patients were primigravidae and $49 \%$ were multigravida. Among $76 \%$ hypertensive patients, $51 \%$ were multigravida. In Oligohydramnios group, majority (58\%) were Primigravida.

\begin{tabular}{|c|c|c|}
\hline $\begin{array}{c}\text { History of } \\
\text { Hypertension }\end{array}$ & No. of Cases & Percentage \\
\hline Previous pregnancy & 7 & $9.2 \%$ \\
\hline Family history & 2 & $2.6 \%$ \\
\hline
\end{tabular}

Table 6. Patients with Earlier History of PIH and with Family History of Hypertension

Patients with earlier History of PIH and with Family History of Hypertension

In present study 76\% (76 patients) were hypertensives. Among them, 9.2\% had H/o PIH in previous pregnancy and $2.6 \%$ had positive family history.

\begin{tabular}{|c|c|c|}
\hline S/D Ratio & No of Cases & Percentage \\
\hline$<2.6$ & 76 & $76 \%$ \\
\hline$>2.6$ & 24 & $24 \%$ \\
\hline Total & $\mathbf{1 0 0}$ & $\mathbf{1 0 0} \%$ \\
\hline \multicolumn{3}{|c|}{ Table $\mathbf{7 a}$} \\
\hline
\end{tabular}

\section{Uterine artery $S / D$ ratio}

Artery S/D r Out of 100 patients with uterine artery Doppler study, 24\% (24 patients) had elevated S/D ratio more than 2.6 .

\begin{tabular}{|c|c|c|}
\hline RI & No. of Cases & Percentage \\
\hline Elevated & 11 & $11 \%$ \\
\hline Normal & 89 & $89 \%$ \\
\hline Total & $\mathbf{1 0 0}$ & $\mathbf{1 0 0} \%$ \\
\hline Table 7b. Uterine Artery RI Distribution \\
\hline
\end{tabular}

\section{Uterine artery RI Distribution}

Out of 100 patients, $11 \%$ (11 patients) had elevated RI > 0.68 and in $89 \%$ (89 patients) it was within normal limits.

\begin{tabular}{|c|c|c|}
\hline PI & No. of Cases & Percentage \\
\hline Elevated & 39 & $39 \%$ \\
\hline Normal & 61 & $61 \%$ \\
\hline Total & $\mathbf{1 0 0}$ & $\mathbf{1 0 0 \%}$ \\
\hline \multicolumn{2}{|c|}{ Table 7b. Uterine Artery RI Distribution } \\
\hline
\end{tabular}

\section{Umbilical artery PI}

In 39\% (39 patients) of the patients umbilical artery PI was elevated $>1$, whereas it was within normal range in $61 \%$ (61 patients).

\begin{tabular}{|c|c|c|}
\hline Parameter & No. of Cases & Percentage \\
\hline Absence EDF & 3 & $3 \%$ \\
\hline Reversal EDF & 6 & $6 \%$ \\
\hline Total & $\mathbf{9}$ & $\mathbf{9 \%}$ \\
\hline Table 8. Absence or Reversal of End Diastolic Velocity in \\
Umbilical Artery \\
\hline
\end{tabular}

\begin{tabular}{|c|c|c|}
\hline Flow velocity Profile & No. of Cases & Percentage \\
\hline Normal & 42 & $42 \%$ \\
\hline Abnormal & 58 & $58 \%$ \\
\hline Total & $\mathbf{1 0 0}$ & $\mathbf{1 0 0 \%}$ \\
\hline Table 9a. Doppler Findings in Umbilical Artery using all \\
Parameters \\
\hline
\end{tabular}

Doppler findings in Umbilical Artery using all Parameters

Out of $58 \%$ having abnormal diastolic flow in umbilical artery, $49 \%$ had decreased diastolic flow, absence of end diastolic flow velocity in 3\% (3 patients) and reversal in $6 \%$ of patients.

\section{Adverse Perinatal Outcome in Present Study}

Out of 100 cases, 34 patients had preterm delivery, 3 had still birth, foetal distress was present in 24 cases, meconium staining in 40 cases, low APGAR in 19 cases, 38 needed NICU admission and neonatal deaths were noted.

\section{DISCUSSION}

Present study comprises of 100 high risk cases and among these, maximum number of patients were in the mean age group of 21-25 years. Only $30 \%$ of the patients were booked in our hospital. As this is a tertiary centre, most cases were referred and presented as unbooked emergencies. $46 \%$ of patients belonged to low socioeconomic class, as per modified Kuppuswamy classification.

Out of 100 high risk cases, 56\% had hypertension, 24\% had Oligohydramnios and $20 \%$ had both hypertension and Oligohydramnios.

Among 76 patients having hypertension, $44.7 \%$ were in the mean age group of 21-25 years. These results were similar to the study conducted by Smitha k et al ${ }^{6}$.

Patients were recruited for the study irrespective of their parity, out of 100 patients, $51 \%$ of patients were primigravidae and $49 \%$ were multigravida. Among $76 \%$ hypertensive patients, $51 \%$ were multigravida. In Oligohydramnios group, majority (58\%) were Primigravida.

Out of $76 \%$ having hypertension, $9.2 \%$ had hypertension in previous pregnancy and $2.6 \%$ had positive family history, supported by study Ayaz A et al ${ }^{7}$ having $5.4 \%$ and $1.3 \%$ positive past history and family history respectively.

In all these high risk cases, Doppler studies were conducted.

In uterine artery Doppler study, abnormal RI $>0.6$ was present in $11 \%$, PI $>1.1$ in $25 \%$ and S/D ratio $>2.6$ in $24 \%$. $39 \%$ showed persistence of notching in uterine artery. Contrast to this study, Fleischer et al ${ }^{8}$ noted abnormal RI, PI, S/D ratio in $93 \%, 85 \%, 90 \%$ respectively and suggested that persistent diastolic notch, elevated S/D, RI, PI are associated with PIH and raised S/D ratio indicates poor foetal outcome.

Gerorge Farmakides in Doppler velocimetry and hypertension states that S/D ratio RI, PI increases but also states that S/D ratio is better indicator for monitoring foetus.

Umbilical artery Doppler study revealed, abnormal RI $>0.6$ in $58 \%$, consistent with studies conducted by Das $\mathrm{K}$ et al $^{9}(50 \%)$ and Hazra et al ${ }^{10}(76 \%)$ respectively. PI $>1$ was noted in $39 \%$ in present study, consistent with Mishra et al ${ }^{11}$ in $46 \%$ and Smitha $\mathrm{k}$ et al in $54 \%$ respectively. Abnormal S/D ratio $>3$ was present in $29 \%$.

Out of 58\% having abnormal umbilical artery Doppler in present study, 51\% had IUGR, 10\% had low APGAR $<7$ at 1 
min and 5 min, $48.2 \%$ needed NICU admission and $12 \%$ had perinatal deaths.

Absent diastolic flow in umbilical artery was present in $3 \%$, out of which $66 \%$ had perinatal mortality. Reversal flow was noted in $6 \%$ and all cases had perinatal death. Similar to this was noted in studies performed by Smitha $\mathrm{k}$ et al showing $18 \%$ with absent diastolic flow, out of which $27.3 \%$ had perinatal mortality. $8 \%$ with reversal diastolic flow and all cases had perinatal death.

MCA Doppler studies revealed low RI $<0.75$ in $71 \%$, supported by Das k et al ${ }^{9} 54 \%$ and Hazra et al ${ }^{10} 62 \%$. PI $<1.2$ in $40 \%$, supported by Smitha $\mathrm{k}$ et al $68 \%$. Since middle cerebral artery of foetus is last to get affected in PIH, Oligohydramnios due to brain sparing effect, it is expected that middle cerebral artery PI will be normal in second trimester and third trimester. Reduced PI in MCA indicates presence of decreased impedance to cerebral circulation. Such foetuses are at high risk of poor perinatal outcome.

All these high-risk cases were monitored, and termination of pregnancy was planned according to biochemical parameters, gestational age, Doppler studies.

Majority of the patients, $66 \%$ were at the mean gestational age of $37-40$ weeks and $34 \%$ were preterm. Consistent to study by Pires et al ${ }^{12}$ where $59.7 \%$ were preterm and $39.4 \%$ were $>37$ weeks.

$40 \%$ underwent vaginal delivery, out of which $50 \%$ were induced, $50 \%$ had spontaneous onset. $7.5 \%$ needed instrumental delivery. $60 \%$ had caesarean section, out of which $40 \%$ were due to foetal distress, $25 \%$ for failed induction, $16.6 \%$ for CPD and failure to progress each, 1.6\% for breech presentation. Consistent to this was noted by Pires et al ${ }^{12}$ with caesarean section and vaginal delivery in $74.4 \%$ and $25.6 \%$ respectively.

$58 \%$ of neonates in our study had a mean birth weight of $<2.5 \mathrm{~kg}$. Meconium staining was present in $40 \%$ of babies and low APGAR $<7$ at $1 \mathrm{~min}$ and 5 mins in 19\%. NICU admission was needed for $38 \%$ of babies. $62 \%$ were shifted mother side and did not need NICU admission. Among 38\%, $10 \%$ had RDS, $20 \%$ for MAS and $8 \%$ for VLBW.

Of the 38\% requiring NICU admissions, 30\% were discharged and $8 \%$ neonatal deaths were present. of 30 neonates being discharged, 25 needed NICU stay for less than 1 week, 4 for upto 10 days and 1 neonate for upto 1 month for severe IUGR with birth weight $1.1 \mathrm{~kg}$.

$12 \%$ perinatal mortality was observed in my study. $1 \%$ had IUD, $3 \%$ of still births and $8 \%$ neonatal deaths of them, 3 were due to RDS, 3 due to MAS and 2 had early neonatal sepsis consistent to this was observed by Das k et al ${ }^{49}$ with $2.7 \%$ with IUD, no still births, $5.4 \%$ with early neonatal deaths respectively. Other study by Pires et al had $2 \%$ with IUD, no still births, $6.5 \%$ with early neonatal deaths.

In patients who had perinatal deaths as foetal outcome, most of them showed absent/reversal EDF, raised S/D ratio and PI in umbilical artery and majority showed decreased PI in MCA.

No maternal mortality was noted in our study.

\section{CONCLUSION}

- The objective of every pregnancy is to give birth to a live and healthy baby.

- $\quad$ High risk pregnancy is an obstetric emergency. One of the main aims of routine antenatal care is to identify the foetus at risk in order to apply clinical interventions which result in reduced perinatal morbidity and mortality.

- $\quad$ Currently, Doppler ultrasound, an evolved noninvasive technique, is widely used to assess blood flow in both foetal and maternal hemodynamic circulatory function. Due to its feasibility and safety, this new innovation has now become an effective instrument for foetal surveillance. Colour Doppler and spectral Doppler studies have further added a new dimension and has provided information which has helped in improved management of obstetric cases that were earlier hither to not salvageable.

- Present study conducted in high risk pregnancies with Doppler parameters, revealed those with abnormal Doppler study had an adverse outcome.

- To conclude, Doppler study has got a better prediction of adverse perinatal outcome and thus provide the obstetrician adequate time during which early intervention can be made to improve foetal outcome.

\section{REFERENCES}

[1] Phelan JP, Ahn MO, Smith CV, et al. Amniotic fluid index measurements during pregnancy. J Reprod Med 1987;32(8):601-4.

[2] Jeng CJ, Lee JF, Wang KG, et al. Decreased amniotic fluid index in term pregnancy. Clinical Significance. J Repord Med 1992;37(9):789-92.

[3] Sibai BM, Hauth J, Caritis S, et al. Hypertensive disorders in twin versus singleton gestations. National Institute of Child Health and Human Development Network of Maternal - Foetal Medicine Units. Am J Obstet Gynecol 2000;182(4):938-42.

[4] Iandonald, Mishra R. Hypertensive disorders in pregnancy. In practical obstetric problems. $6^{\text {th }}$ edn New Delhi: 2007: p. 280-309.

[5] Sibai BM, Ramadon MK, Usta I, et al. Maternal morbidity and mortality in 442 pregnancies with hemolysis, elevated liver enzymes and lower platelets (HELLP Syndrome). Am J Obstet Gynecol 1993;169(4):1000-6.

[6] Smitha K, Sowmya K, Malathi T. Study of Doppler waveforms in pregnancy induced hypertension and its correlation with perinatal outcome. Int J Reprod Contracept Obstet \& Gynecol 2014;3(2):428-33.

[7] Ayaz A, Muhammad T, Hussain SA, et al. Neonatal outcome in pre-eclamptic patients. J Ayub Med Coll Abbottabad 2009;21(2):53-5.

[8] Fleisher A, Schulman H, Farmakides G, et al. Uterine artery Doppler velocimetry in pregnant women with hypertension. Am J Obstet \& Gynecol 1986;154(4):806-13.

[9] Das SK, Biswas T. Foetal cerebral umbilical Doppler ratio in prediction of adverse perinatal outcome in patient with pre-eclampsia. JMSCR 2014;2(6):143847.

[10] Hazra SK, Dash KK, Chaudhuri A, et al. A prospective study of Doppler velocimetry in pregnancy-induced hypertension in a rural population of a developing country. J Basic Clin Reprod Sci 2013;2:127-31. 


\section{Jemds.com}

[11] Mishra D, Sakhi P, Saraf A, et al. Role of obstetric Doppler in prediction of adverse perinatal outcome in intrauterine growth retardation and pregnancy induced hypertension. Sch J App Med Sci 2013;1(6):1016-20.

\section{Original Research Article}

[12] Pedro P, Latham AEF, de MSK, et al. Foetal and placental Doppler velocimetry in hypertensive pregnant women and perinatal outcomes according to gestational age. Radiol Bras 2010;43(3):155-60. 